\title{
Closing the Aboriginal child injury gap: targets for injury prevention
}

\author{
Holger Möller, ${ }^{1}$ Kathleen Falster, ${ }^{1,2,3}$ Rebecca Ivers, ${ }^{4}$ Michael O. Falster, ${ }^{1}$ Kathleen Clapham, ${ }^{5}$ Louisa Jorm ${ }^{1}$
}

U nintentional injuries are a leading cause of child morbidity and mortality in Australia, ${ }^{1-3}$ and a major contributor to the health gap between Aboriginal and non-Aboriginal children. ${ }^{4-8}$ These injuries are highly preventable ${ }^{9}$ and at population level legislative measures, as well as product modification, and safety campaigns have contributed to a decrease in injury rates. ${ }^{10-14}$

However, broad population level injury prevention strategies alone may not reduce health inequalities and may even increase them through differential access to, uptake of, or effectiveness of interventions between social groups. ${ }^{10,15}$ In contrast, programs specifically targeted at vulnerable population groups can help reduce injury inequalities. ${ }^{14}$ Despite this, there are limited targeted injury prevention programs for Aboriginal children in Australia to date, ${ }^{16,17}$ and there are few studies to inform the development of such programs. ${ }^{18,19}$

The development of injury prevention programs for Aboriginal children requires knowledge of leading injury mechanisms in terms of their burden and inequalities, as well as the age groups at greatest risk. This detailed level of information is currently not available in Australia. ${ }^{20}$

Previous Australian studies have reported injury rates in Aboriginal children for external cause groups such as transport, falls, burns and poisoning..$^{5-7,16-18}$ However, more specific injury mechanisms included within these groups might be of differing priority to policymakers and may require different injury prevention strategies. For example,

\begin{abstract}
Objective: To describe the leading mechanisms of hospitalised unintentional injury in Australian Aboriginal children and identify the injury mechanisms with the largest inequalities between Aboriginal and non-Aboriginal children.

Methods: We used linked hospital and mortality data to construct a whole of population birth cohort including 1,124,717 children (1,088,645 non-Aboriginal and 35,749 Aboriginal) born in the state of New South Wales (NSW), Australia, between 1 July 2000 and 31 December 2012. Injury hospitalisation rates were calculated per person years at risk for injury mechanisms coded according to the ICD10-AM classification.
\end{abstract}

Results: The leading injury mechanisms in both groups of children were falls from playground equipment. For 66 of the 69 injury mechanisms studied, Aboriginal children had a higher rate of hospitalisation compared with non-Aboriginal children. The largest relative inequalities were observed for injuries due to exposure to fire and flame, and the largest absolute inequalities for injuries due to falls from playground equipment.

Conclusion: Aboriginal children in NSW experience a significant higher burden of unintentional injury compared with their non-Aboriginal counterparts.

Implications for Public Health: We suggest the implementation of targeted injury prevention measures aimed at injury mechanism and age groups identified in this study.

Key words: Indigenous, injury, child

the external cause group falls includes falls in the home as well as falls from playground equipment. Whereas the risk of falls in the home can be reduced by the family through childproofing measures and reduction of fall hazards, public playgrounds are maintained by the council and their design is regulated by the Australian standard for playground equipment. ${ }^{21}$

None of the previous Australian studies has reported injury rates for Aboriginal children disaggregated for ages less than five years. ${ }^{20}$ This information is important, because previous Australian studies have shown that very young children are at the greatest risk of some injuries, such as poisoning ${ }^{22}$ and burns. $^{23}$

Against this background, we explored hospitalisation for unintentional injury in a whole-of-population cohort of children aged 0-13 years in the state of New South Wales (NSW), Australia, to address the questions: 1) Which are the leading injury mechanisms resulting in hospitalised injury in Aboriginal children? 2) Which injury mechanisms resulting in hospitalised injury have the largest absolute and relative inequalities between Aboriginal and non-Aboriginal children?; and 3) Which age groups are at greatest risk of hospitalisations?

\footnotetext{
1. Centre for Big Data Research in Health, UNSW Kensington Campus, New South Wales

2. National Centre for Epidemiology and Population Health, The Australian National University, Australian Capital Territory

3. The Sax Institute, New South Wales

4. The George Institute for Global Health, New South Wales

5. The Australian Health Services Research Institute, University of Wollongong, New South Wales

Correspondence to: Mr Holger Möller, Centre for Big Data Research in Health, Level 1 AGSM Building, UNSW Kensington Campus, Sydney, NSW 2052;

e-mail: holger@unsw.edu.au

Submitted: December 2015; Revision requested: May 2016; Accepted: June 2016

The authors have stated they have no conflict of interest.
} 


\section{Methods}

\section{Setting}

NSW is the most populous state in Australia, with an estimated $6,816,087$ residents $(1,318,990$ children aged $0-14$ years $)$ in 2006. ${ }^{24}$ NSW has the largest number of indigenous inhabitants and at the 2006 Census, $2.2 \%$ of NSW residents self-identified as Aboriginal and/or Torres Strait Islander (7.0\% of children aged 0-14 years), referred to here as 'Aboriginal', because Aboriginal people are the original inhabitants of NSW. ${ }^{25}$

\section{Data sources}

This study used hospital data from the NSW Admitted Patient Data Collection (APDC) linked with mortality data from the NSW Register of Births, Deaths and Marriages (RBDM). The APDC includes records for all separations (discharges, transfers and deaths) from all NSW public and private sector hospitals and day procedure centres. Patient demographics and multiple diagnoses and procedures are recorded for each separation and coded according to the Australian modification of the International Statistical Classification of Diseases and Related Problems, 10th revision (ICD-10-AM) ${ }^{26}$ The RBDM captures details of all deaths registered in NSW. Probabilistic linkage of the datasets was performed by the NSW Centre for Health Record Linkage ${ }^{27}$ and de-identified datasets including linked APDC and RBDM records from July 2000 to March 2014 were supplied to the researchers for analysis.

\section{Participants}

The linked data were used to define a cohort of children for the analysis. This included all children resident in NSW, who were born in a hospital in NSW between 1 July 2000 and 31 December 2012. Birth records were identified from the ADPC dataset using the following criteria: "live born infant" (ICD10-AM code $Z 38)^{26}$ in any diagnosis field or a date of birth greater than or equal to the admission date and less than or equal to the separation date $(1,124,717$ children, of which 35,779 were Aboriginal). Children were excluded if their sex was coded as indeterminate or missing or there were discrepancies in their date of birth and admission and/or separation date on their birth record (293 non-Aboriginal and 30 Aboriginal children). A similar proportion of excluded Aboriginal and nonAboriginal children were hospitalised for an unintentional injury (7\% of non-Aboriginal and $11 \%$ of Aboriginal children) compared with the study cohort. The final study cohort consisted of $1,124,717$ children $(1,088,645$ non-Aboriginal and 35,749 Aboriginal).

\section{Analysis variables}

The study outcome was first hospitalisation for unintentional injury, defined as a principal diagnosis of injury (ICD10-AM code of SOO-T75 or T79) and an external cause code of unintentional injury (ICD10-AM code of V01-X59, Y85-Y86). Unintentional injuries were analysed overall, according to external cause groups (Supplement 1, TableS1), ${ }^{28}$ and by injury mechanism coded by the first three characters in the ICD10-AM. ${ }^{26}$ Aboriginal status was derived from the child's birth record.

\section{Statistical analysis}

Person-years at risk were calculated from the date of birth to the first of the following events: hospitalisation for the relevant unintentional injury (all unintentional injuries combined, each specific injury mechanism), death, or end of follow-up (31 March 2014). Incidence rates were calculated by dividing the number of first unintentional injury hospital admissions by the person years accumulated for Aboriginal and non-Aboriginal children. Differences in injury hospitalisation between Aboriginal and non-Aboriginal children were calculated as the difference in incidence rates (absolute inequality) and rate ratios (relative inequality).. ${ }^{29}$ The absolute inequality was calculated by subtracting the incidence rate in Aboriginal children from that in non-Aboriginal children, and the relative inequality by dividing the incidence rate for Aboriginal by that for non-Aboriginal children. Confidence intervals were calculated assuming a Poisson distribution for the first injury hospitalisation. Kaplan Meier methods using age as the time scale were used to assess the probability of being hospitalised for an unintentional injury in the two groups of children. The log rank test was used to examine difference in time to first injury hospitalisation between Aboriginal and nonAboriginal children. Statistical analyses were carried out using Stata $12^{30}$ and SAS 9.3..$^{31}$

\section{Ethical approval}

Ethics approval for the study was given by the Population Health Services Research Ethics Committee, the Aboriginal Health and Medical Research Council Ethics Committee, and the University of Western Sydney Ethics Committee.

\section{Results}

\section{Characteristics of cohort and hospitalisation by external cause groups}

A total of $1,124,717$ children were included in the cohort; of these 35,749 children (3.2\%) were Aboriginal. Of children in the cohort 75,393 non-Aboriginal (6.9\%) and 3,412 Aboriginal (9.5\%) children were admitted to a NSW hospital for any first unintentional injury from 2000 to 2014. The leading external cause groups resulting in hospitalisation in Aboriginal boys were falls (715.7 per 100,000 person-years), injuries due to causes other specified (205.0 per 100,000 person-years) and being struck by or against ( 168.3 per 100,000 person-years). In Aboriginal girls they were falls ( 546.3 per 100,000 personyears), injuries due to causes other specified (182.1 per 100,000 person-years) and poisoning (134.9 per 100,000 person-years). (Supplement 2, Table S2, FigureS2a)

Overall, Aboriginal children had a 1.6 times higher risk of hospitalisation for any unintentional injury (RR 1.6, 95\% Cl 1.5-1.6) compared with non-Aboriginal children, which equalled an absolute difference of 580.8 (95\% Cl 549.1-613.8) hospitalisations per 100,000 person-years. Among the external cause groups, the largest relative differences between Aboriginal and nonAboriginal children were observed for boys for exposure to smoke, fire and flames (RR $6.4,95 \% \mathrm{Cl} 4.5-9.0$ ), poisoning (RR 3.1, 95\% $\mathrm{Cl}$ 2.6-3.5) and contact with heat and hot substances (RR 2.3, 95\% Cl 1.9-2.7); and for girls for exposure to smoke, fire and flames (RR 5.8, 95\% Cl 3.6-9.1), drowning (RR 2.9, 95\% $\mathrm{Cl} 1.8-4.5)$ and poisoning (RR $2.895 \% \mathrm{Cl}$ 2.33.3). The largest absolute difference between Aboriginal and non-Aboriginal children were observed for boys for falls $(181.2,95 \% \mathrm{Cl}$ 157.5-207.5), poisoning (112.2, 95\% Cl 93.9133.0) and causes other specified $(82.1,95 \%$ Cl 66.6-100.1); and for girls for falls (124.8, $95 \% \mathrm{Cl} 104.8-147.5)$, poisoning $(86.4,95 \% \mathrm{Cl}$ 170.1-105.5) and causes other specified (80.4, 95\% Cl 64.6-98.8) (Supplement 2, Table S2, Figure S2a, S2b).

\section{Age patterns in injury risk by external cause groups}

The risk of unintentional injury hospitalisation increased from the age of one year up to the 
age of 13 years (the maximum age of children in the cohort). Aboriginal children had a significantly higher risk of hospitalisation for all unintentional injuries combined and all major external cause groups studied $(p<0.001)$ (Figure 1).

The age pattern and inequality in risk of hospitalisation between Aboriginal and non-Aboriginal children varied according to external cause group. For injuries caused by fire, flame, heat and hot substances and poisoning, risk of hospitalisation increased steeply after the age of one year and plateaued at the age of three years in both Aboriginal and non-Aboriginal children. The risk of fall injury hospitalisations increased from the age of one year and kept increasing with age in both groups of children. For transport injuries, injuries due to cutting and piercing, injuries due to being struck or against, injuries due to natural and environmental causes and injuries due to other causes specified, the risk of hospitalisation increased with age, as did the inequality between Aboriginal and non-Aboriginal children (Figure 1). For these external cause groups the risk of hospitalisation and inequalities increased more steeply from the age of four years onwards.

\section{Injury mechanisms}

The leading injury mechanisms in both groups of children were falls involving playground equipment (139.7 per 100,000 in Aboriginal and 101.3 per 100,000 in non-Aboriginal children) and foreign body being stuck in eye or natural orifice ( 60.1 per 100,000 in Aboriginal and 49.3 per
Figure 1: The probability of hospitalization for unintentional injury by age and external cause group in a cohort of Aboriginal and non-Aboriginal children in NSW, Australia, 2000-2014.
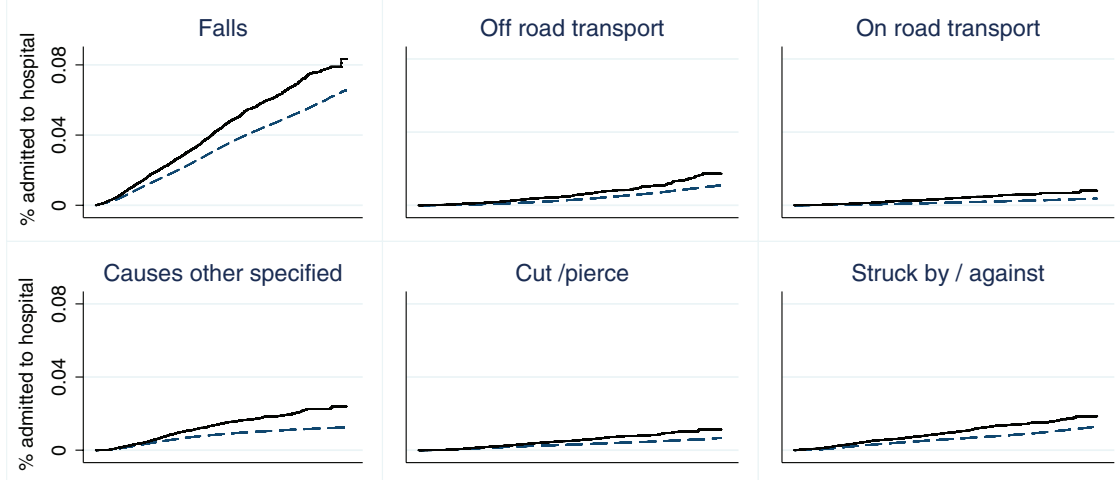

ut /pierce

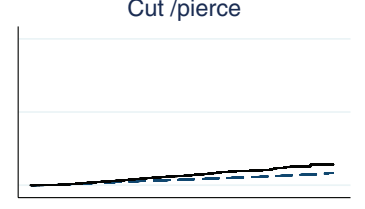

Struck by / against
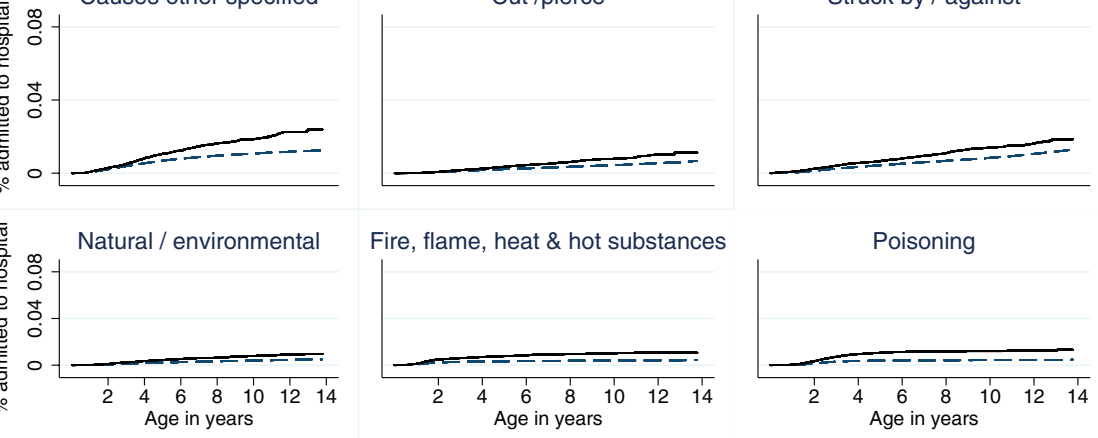

100,000 in non-Aboriginal children) (Figure2, Supplement 3, Tables S3). Different types of fall injuries contributed the largest number of hospitalisations among the 20 leading injury mechanisms in both groups of children (Figure 2).

For 33 out of the 69 injury mechanisms for which results are shown in the detailed analysis, Aboriginal children had a more than two-fold increased risk of hospitalisation compared with non-Aboriginal children (Supplement 3, Table S3). The largest relative inequalities in hospitalisation were for injuries due to ignition or melting of clothing (RR
9.7, 95\% Cl 3.2-24.8), exposure to ignition of highly flammable material (RR, $7.195 \% \mathrm{Cl}$ 2.915.5) and exposure to controlled fire not in building (RR, 7.1, 95\% Cl 3.8-12.2) (Figure 3).

In comparison, the largest absolute inequalities were observed for falls from playground equipment $(38.4,95 \% \mathrm{Cl}$ 31.2-46.8), foreign body being stuck in eye or natural orifice $(38.1,95 \% \mathrm{Cl} 30.9$ 46.5) and poisoning by other medical and biological substances $(32.2,95 \% \mathrm{Cl} 25.6-39.9)$ (Supplement 3, Figure S3).

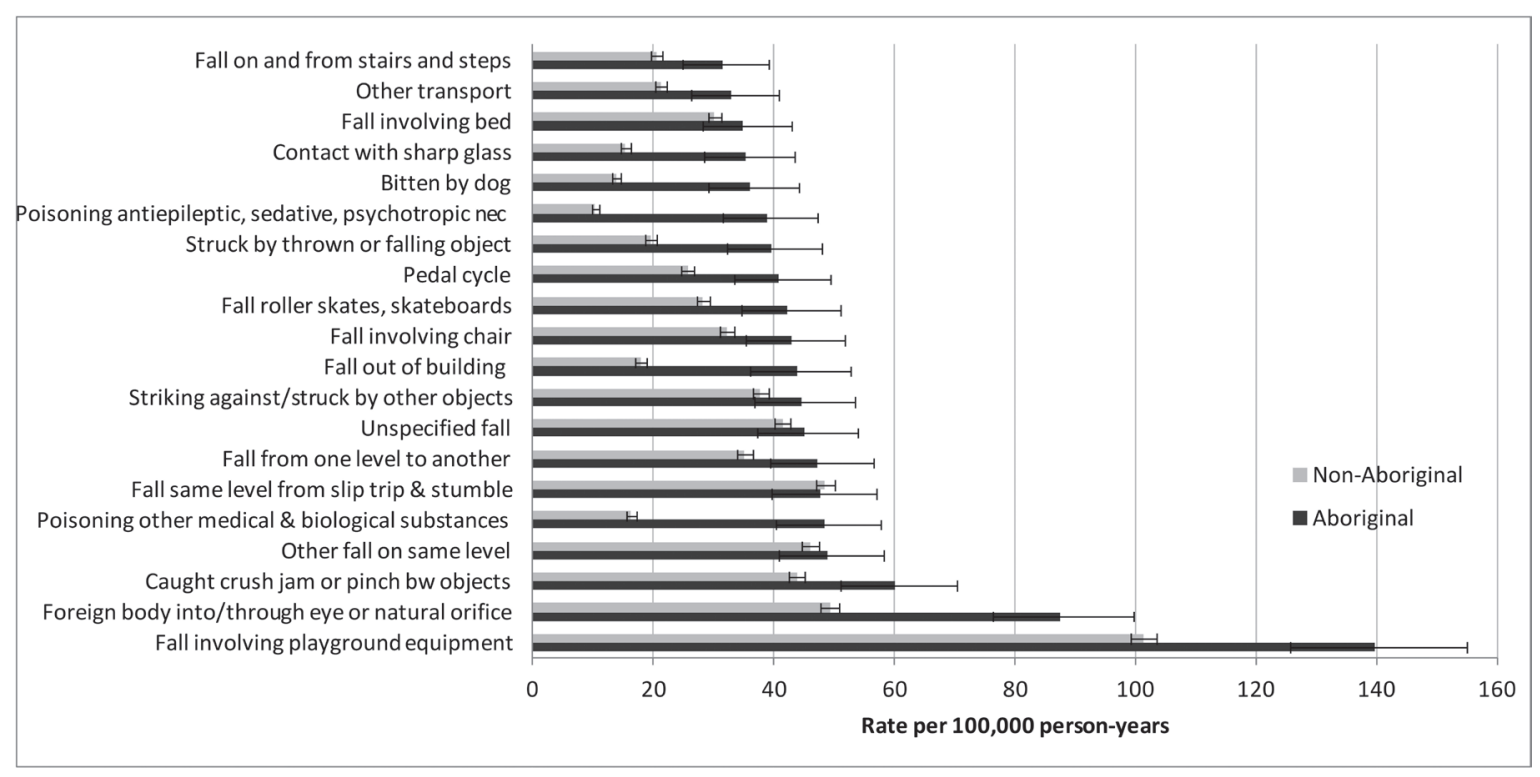

Figure 2: Rates of injury hospitalisation for 20 leading injury mechanisms in a cohort of children of Aboriginal and nonAboriginal children in NSW, Australia, 2000-2014. 


\section{Discussion}

Australian Aboriginal children experience a significantly higher burden of unintentional injury hospitalisation compared with their non-Aboriginal counterparts. In this study we identified leading injury mechanisms in terms of their burden and inequalities, highlighting target areas for injury prevention.

Falls from playground equipment were the leading cause of unintentional injury hospitalisations in both Aboriginal and non-Aboriginal children. These findings are in line with those reported in Australian whole-of-population studies. ${ }^{1,32}$ The second leading mechanism of injury hospitalisation was foreign objects getting stuck in the child's body, which is included in the external cause group causes other specified. Young children are naturally curious and may put objects into their mouths, or insert them in their ears and up their noses, requiring hospitalisation to remove these items. The large number of child injury hospitalisations due to the external cause group 'other specified' has been previously highlighted.' However, our study is the first to show the contributions of the different injury mechanisms summarised within this group.

Aboriginal children had a higher risk of hospitalisations for 66 of the 69 injury mechanisms presented in our study and for almost half of all injury mechanisms Aboriginal children had a two-fold or higher increased risk of hospitalisations compared with non-Aboriginal children. The largest relative inequalities between Aboriginal and non-Aboriginal children in our study were for injuries caused by exposure to fire and flames and poisonings by drugs and chemical substances. In comparison the largest absolute inequalities were for falls from playground equipment and foreign objects getting stuck in the child's body.

Previous Australian studies have also reported large relative inequalities for the external cause groups thermal injuries and poisoning, ${ }^{5,6,8}$ but none have looked at the different injury mechanism within these groups. Our study showed much larger inequalities for fire and flame injuries than for contact with hot substances, an important distinction because different prevention strategies are applicable. No other Australian studies have compared absolute inequalities for injury mechanisms between Aboriginal and non-Aboriginal children in Australia to date. $^{20}$

The risk of injury varied by age for the different external cause groups in our study. No previous Australian studies have provided a disaggregated analysis of differences in unintentional injury between Aboriginal and non-Aboriginal children for children aged less than 5 years. ${ }^{20}$ However a previous study from NSW showed, similar to our findings, highest rates of injury hospitalisations in Aboriginal children for 0-4 year olds for poisoning, 5-14 year olds for falls, 0-9 year olds for burns and 10-14 year olds for transport. ${ }^{6}$ Whole-of-

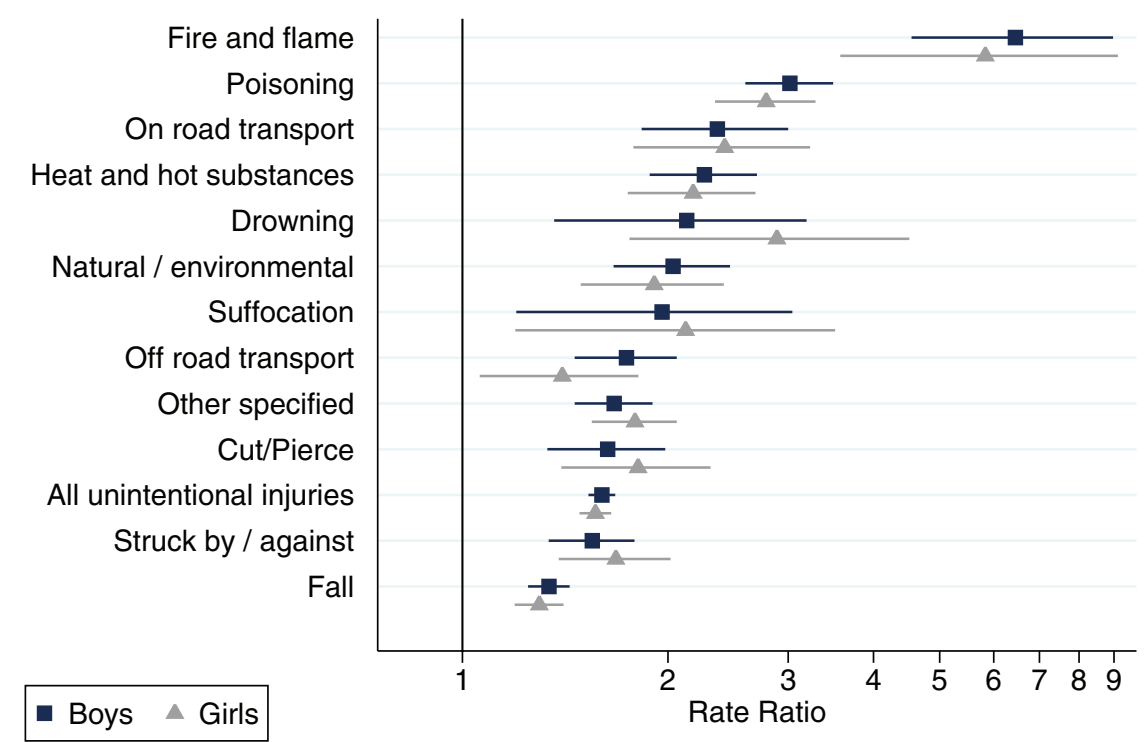

population studies from Australia have also highlighted the high injury burden of burns and poisoning in young children. ${ }^{33}$

\section{Strengths and limitations}

To our knowledge this is the first whole-ofpopulation cohort study investigating the contribution of different mechanisms to injury hospitalisations in Aboriginal children in Australia.

Our study, like others using routinely collected hospital data, was restricted to the more severe injuries resulting in hospitalisation. ${ }^{6,7}$ At present, there is no available source of data on injuries treated in the primary care setting in Australia. Potential inaccuracies in the external cause coding in hospital data have been highlighted previously. ${ }^{34,35}$

Recording of Aboriginal status in routinely collected data can vary between data collections and over time. ${ }^{36}$ Compared with previous Australian studies of cross sectional design, ${ }^{5-7,32,37-40}$ our study derived both injury events and person-years at risk from hospital data for the cohort, thus using the same method of identification of Aboriginal children in the numerator and denominator for calculation of rates. As a consequence, our study avoided the problem of numeratordenominator bias arising from differences in the way that Aboriginal status is recorded in hospital ${ }^{41}$ and population census data. ${ }^{42}$

In addition, under-reporting of Aboriginal status in routinely collected data is a recognised problem, ${ }^{43,44}$ that can lead to under-ascertainment of health outcomes, including hospitalisation for injury, in Aboriginal children. We used Aboriginal status from the birth record in our analysis to minimise the effect of differential misclassification bias whereby children who are admitted to hospital more frequently would have had more opportunity to be recorded as Aboriginal.

Higher rates of hospital in Aboriginal children may also reflect differences in access to other health care providers and services. ${ }^{45} \mathrm{~A}$ higher proportion of Aboriginal children live in rural and remote areas and children from these areas might be more likely to be treated as in-patients as they have longer travelling distance to the hospital, thus making it more difficult to return as day patients. ${ }^{46}$

Additionally, migration of children interstate after birth, or admission to hospitals in other Australian states, may have further biased 
our risk estimates in a downward direction. Although population mobility is lower for children than at older ages, there is greater mobility in the Aboriginal compared with non-Aboriginal population. ${ }^{47}$

Finally, we did not adjust for multiple comparisons in our analysis, because there is a strong argument for not adjusting for multiple comparisons when the data under investigation are observations of nature, as this will lead to fewer errors in interpretation. ${ }^{48}$

\section{Implications for practice}

Our research suggests that there is substantial scope to reduce child injuries and inequalities in injury between Aboriginal and nonAboriginal children.

At a population level, legislative measures such as modification of medicine and poison packaging, fencing of swimming pools, regulation of hot water temperature, use of child passenger restraints and booster seats and installation of smoke alarms have been successful in reducing child injuries..$^{10-13,49,50}$ However, our findings suggest that these have not been successful in reducing injury inequalities.

Targeted injury prevention programs ${ }^{19}$, as well as environmental modifications, including assuring that playgrounds comply with safety standards, ${ }^{21}$ present ways to reduce injuries and inequalities observed in this study.

Falls involving playground equipment were the leading injury mechanisms in both groups of children in our study. Although compliance of playground equipment with Australian and New Zealand safety standards has improved ${ }^{51}$ shock absorbing properties of under surfaces have been found to be often insufficient or not sufficiently maintained. ${ }^{51,52}$ Lack of resources is a main barrier to adequate maintenance of playgrounds ${ }^{52}$ and maintenance may be lower in disadvantaged and non-metropolitan areas $\mathrm{s}^{47,48}$ where a larger proportion of Aboriginal children live. ${ }^{52,53}$ Ensuring that playgrounds meet and are maintained to appropriate safety standards ${ }^{21}$ are key measures to reduce the large number of hospitalisations due to falls from playground equipment observed in this study.

However, a large number of the injuries occur in the home environment and young children (aged less than 3 years) were at greatest risk for some of these injuries. Home safety practices to reduce hazards in the living environment by for example storage of poisonous substances out of reach of children, installation of safety equipment such as stair gates and window locks and close supervision of small children are commonly promoted measures to reduce these injuries. ${ }^{9,54}$

However uptake of safety measures requires knowledge of potential hazards and safety practices to address these, as well as the financial means to afford safety equipment. Population level studies have highlighted differential uptake of home safety measures by socioeconomic groups, ${ }^{55}$ indicating the need for prevention measures specifically targeted at disadvantaged families. ${ }^{55,56}$ This might also apply to Australian Aboriginal people, who experience significant social disadvantage. ${ }^{57}$

In order to design targeted injury prevention programs it is important to understand what might contribute to their success. Two recent systematic reviews identified facilitators and barriers to uptake of home safety practices from qualitative and quantitative population based studies, respectively. ${ }^{58,59}$ Barriers identified in these studies were lack of finance to afford and maintain safety devices, lack of knowledge and tools for the installation of safety devices, low literacy, high frequency of moving house, living in rented accommodation where it is difficult to install safety devices, mistrust of officials and motives of person delivering prevention program, design of overly complex prevention programs. ${ }^{58,59}$ Facilitators for the successful delivery of injury prevention programs were strong legislation, design of focused and simple programs with a clear message, promotion of safety measures which are simple to implement, provision of free or low cost safety equipment, being able to modify the accommodation, community involvement, and delivery by a professional trusted by the family. ${ }^{58,59}$ Although these whole-of-population findings are not directly transferrable to Australian Aboriginal communities they highlight important factors for the successful design of injury prevention programs.

Additionally, a recent systematic review showed that multi-facetted interventions targeted at disadvantaged families have the potential to reduce child injury and increase uptake of home safety measures, ${ }^{14}$ and a New Zealand study showed that low-cost home improvement measures can reduce fall injuries. ${ }^{60}$ These findings are encouraging as they indicate that targeted injury prevention measures can indeed be successful in reducing the health inequalities observed in this study. This is supported by the findings of a recent Australian study which showed that integrated educational programs that include access to subsidised child restraints may increase optimal child seat use in communities with a high proportion of Aboriginal and Torres Strait Islander families. ${ }^{61}$

However, with the exception of road transport, ${ }^{61}$ there are few prevention activities that specifically target Aboriginal children. ${ }^{16,62-64}$ Prevention programs for other leading child injury mechanisms as well as for those with large inequalities in Aboriginal communities need to be developed and evaluated. In line with the findings from whole-of-population studies discussed earlier, ${ }^{58,59}$ evidence from studies in Aboriginal communities indicate that in order to be successful, interventions targeted at Aboriginal communities should incorporate Aboriginal views of health and involve communities in their development and implementation. ${ }^{62,65}$ Such programs should also take into consideration the local conditions, geographical location, access to services, distinct cultures and social structures of Aboriginal communities. ${ }^{19,62}$ Moreover injury prevention needs to consider and critically reflect on the broader context and systems in which programs and developed and implemented. ${ }^{6}$ Such an approach would examine and acknowledge the views and cultural practices of those developing and delivering prevention strategies as well as the differences in power relationships which may exist, and attempt to deeply embed the principles of cultural safety throughout all aspects of the design and delivery of injury prevention programs. .7,63,66 $^{6}$

In addition to developing new programs, injury prevention could also be included as a core component into existing early childhood home visiting programs, aiming to support vulnerable families. The effectiveness of multifaceted interventions to reduce injury inequalities has been shown in population studies. ${ }^{14}$ Injury prevention could also be included in the strategy to close the Aboriginal health gap. ${ }^{68}$

The underlying causes of child injury are complex. Past policies of colonisation and dispossession have led to a cycle 
of disadvantage, poor education, high unemployment, low income, separation of families, and overcrowded living conditions in Aboriginal peoples, ${ }^{19}$ all of which have been associated with an increased risk of child injury, ${ }^{9,69,70}$ This indicates that injury prevention also needs to address the social determinants of health to improve Aboriginal child health and to reduce barriers accessing services and programs.

\section{Conclusion}

Aboriginal children in NSW experience a significant higher burden of unintentional injury compared with their non-Aboriginal counterparts. We suggest the implementation of targeted injury prevention measures aimed at injury mechanism and age groups identified in this study, in addition to broader population level approaches.

\section{Acknowledgements}

The authors thank Sanja Lujic of University of New South Wales for statistical advice. We acknowledge the NSW Ministry of Health and NSW Registry of Births, Deaths, and Marriages for allowing access to the data, and the NSW Centre for Health Record Linkage for conducting the probabilistic linkage of records.

\section{References}

1. Pointer S. Hospitalised Injury in Children and Young People 2011-12. Injury Research and Statistics Series No.: 91. Canberra (AUST): Australian Institute of Health and Welfare; 2014.

2. Henley G, Harrison JE. Trends in Injury Deaths, Australia: 1999-00 to 2009-10. Injury Research and Statistics Series No.: 74. Canberra (AUST): Australian Institute of Health and Welfare; 2015.

3. Australian Institute of Health and Welfare. Australian Burden of Disease Study: Fatal Burden of Disease 2010. Australian Burden of Disease Study Series No.: 1. Canberra (AUST): AlHW; 2015.

4. Australian Institute of Health and Welfare. Australian Burden of Disease Study: Fatal Burden of Disease in Aboriginal and Torres Strait Islander People 2010. Australian Burden of Disease Study Series No.: 2. Canberra (AUST): AlHW; 2015.

5. Australian Institute of Health and Welfare. Aboriginal and Torres Strait Islander Child Safety. Canberra (AUST): AlHW; 2011.

6. Walter S. Mortality and Hospitilisation Due to Injury in the Aboriginal Population of New South Wales. Sydney (AUST): New South Wales Department of Health Centre for Aboriginal Health; 2010.

7. Henley G, Harrison JE. Injury of Aboriginal and Torres Strait Islander People Due to Transport 2005-2006 to 2009-2010. Injury Research and Statistics Series No.: 85. Catalogue No.:INJCAT 161. Canberra (AUST): Australian Institute of Health and Welfare; 2013.
8. Möller H, Falster $\mathrm{K}$, Ivers $\mathrm{R}$, et al. Inequalities in Hospitalized Unintentional Injury Between Aboriginal and Non-Aboriginal Children in New South Wales, Australia. Am J Public Health. 2016;106(5):899-905.

9 Peden M, Oyegbite K, Ozanne-Smith J, et al. World Report on Child Injury Prevention. Geneva (CHE):World Health Organisation, United Nations International Children's Emergency Fund; 2008.

10. KendrickD, Young B, Mason Jones AJ, et al. Home safety education and provision of safety equipment for injury prevention. Evid Based Child Health. 2013;8(3):761-939.

11. . MacArthur C. Evaluation of Safe Kids Week 2001 Prevention of scald and burn injuries in young children Inj Prev. 2003;9:112-6.

12. Thompson DC, Rivara FP. Pool fencing for preventing drowning in children. Cochrane Database Syst Rev. 2000;(2):CD001047.

13. Zaza S, Sleet DA, Thompson RS, et al. Reviews of evidence regarding interventions to increase use of child safety seats. Am J Prev Med. 2001;21(4S):31-4.

14. Kendrick D, Mulvaney CA, Ye L, Stevens T, Mytton $J A$, Stewart-Brown S. Parenting interventions for the prevention of unintentional injuries in childhood. Cochrane Database Syst Rev. 2013;(3):CD006020.

15. Lorenc T, Petticrew M, Welch V, Tugwell P. What types of interventions generate inequalities? Evidence from systematic reviews. J Epidemiol Community Health. 2013;67(2):190-3.

16. Clapham K. Injury Prevention Activity Among Aboriginal and Torres Strait Islander Peoples Project Report Volume II: Programs, Projects and Actions. Canberra (AUST): Australian Government Department of Health and Ageing; 2003.

17. Clapham K, Senserrick T, Ivers R, Lyford M, Stevenson $M$. Understanding the extent and impact of Indigenous road trauma. Injury. 2008;39 Suppl 5:19-23.

18. Azzopardi PS, Kennedy EC, Patton GC, et al. The quality of health research for young indigenous Australians: Systematic review. Med J Aust. 2013;199(1):57-63.

19. Ivers R, Clapham K, SenserrickT, et al. Injury prevention in Australian Indigenous communities. Injury. 2008;39 Suppl 5:61-67.

20. Möller H, Ivers R, Falster K, Jorm L. Inequalities in unintentional injuries between indigenous and nonindigenous children: A systematic review. Inj Prev. 2015;21(e1):e144-52.

21. Standards Australia. Playground Equipment and Surfacing. Part 1: General Safety Requirements and Test Methods (EN 1176-1:2008, MOD). Brussels (BEL): European Committee for Standardization; 2014

22. Cripps R, Steele D. Childhood Poisoning in Australia. NISU Briefing No.: 5. Canberra (AUST): Australian Institute of Health and Welfare National Injury Surveillance Unit; 2006.

23. DeSilva H, Gabbe B, Callaghan J, Liman J. Burns Registry of Australia and NewZealand Annual Report, 1st July 2012 - 30th June 2013. Melbourne (AUST): Burns Registry of Australia and New Zealand; 2014.

24. Australian Bureau of Statistics. Experimental Estimates of Aboriginal and Torres Strait Islander Australians, June 2006. Canberra (AUST): ABS; 2008.

25. New South Wales Department of Health. Communicating Positively. A Guide to Appropriate Aboriginal Terminology. Sydney (AUST): State Government of NSW; 2004.

26. National Centre for Classification in Health. The International Statistical Classification of Diseases and Related Health Problems. 10th Revision. Australian Modification (ICD-10-AM). Sixth Ed. Sydney (AUST): University of Sydney Faculty of Health Sciences National Centre for Classification in Health; 2008.

27. Centre for Health Record Linkage. Data Linkage System. North Sydney (AUST): CheReL; 2015.

28. Center for Disease Control and Prevention. ICD Framework: External Cause of Injury Mortality Matrix [lnternet]. (GA): CDC; 2002 [cited 2015 Jun 12]. Available from: http://www.cdc.gov/nchs/injury/ice/matrix10. htm
29. Harper S, King NB, Meersman SC, Reichman ME, Breen $\mathrm{N}$, Lynch J. Implicit value judgments in the measurement of health inequalities. Milbank $Q$. 2010;88(1):4-29

30. STATA: Statistical Software: Release 12. College Station (TX) Stata Corporation; 2011.

31. SAS: Statistical Software: Version 9.2. Cary (NC): SAS Institute; 2011.

32. Moorin RE, Hendrie D. The epidemiology and cost of falls requiring hospitalisation in children in Western Australia: A study using linked administrative data. Accid Anal Prev. 2008;40(1):216-22.

33. Pointer S. Trends in Hospitalised Injury, Australia: 1999-00 to 2012-13. Injury Research and Statistics Series No.: 95. Canberra (AUST): Australian Institute of Health and Welfare; 2015.

34. McKenzie K, Enraght-Moony EL, Walker SM, McClure RJ, Harrison JE. Accuracy of external cause-of-injury coding in hospital records. Inj Prev. 2009;15(1):60-4.

35. Davie G, Langley J, Samaranayaka A, Wetherspoon ME. Accuracy of injury coding under ICD-10-AM for New Zealand public hospital discharges. Inj Prev. 2008;14(5):319-23.

36. Australian Bureau of Statistics. Information Paper Perspectives on Aboriginal and Torres Strait Islander Identification in Selected Data Collection Contexts. Canberra (AUST): ABS; 2012.

37. Cercarelli LR. Road crashes involving Aboriginal people in Western Australia. Accid Anal Prev. 1994;26(3):361-9.

38. Cercarelli LR, Knuiman MW. Trends in road injury hospitalisation rates for Aboriginal and non-Aboriginal people in Western Australia, 1971-97. Inj Prev. 2002;8(3):211-5

39. Vimpani G, Doudle M, Harris R. Child accident-mortality in the Northern Territory, 1978-1985. Med J Aust. 1988;148(8):392-5.

40. Silva DT, Ruben AR, Wronski I, Stronach P, Woods M. Excessive rates of childhood mortality in the Northern Territory, 1985-94. J Paediatr Child Health. 1998;34(1): 63-8.

41. Australian Institute of Health and Welfare. National Best Practice Guidelines for Collecting Indigenous Status in Health Data Sets. Catalogue No.: IHW 29. Canberra (AUST): AlHW; 2010.

42. Australian Bureau of Statistics. 3238.0.55.001-Estimates of Aboriginal and Torres Strait Islander Australians, June 2011. Technical Note 1 Estimated Resident Aboriginal and Torres Strait Islander Population-Method of Calculation. Canberra (AUST): ABS; 2013.

43. Randall DA, Lujic $S$, Leyland AH, Jorm LR. Statistical methods to enhance reporting of Aboriginal Australians in routine hospital records using data linkage affect estimates of health disparities. Aust NZJ Public Health. 2013;37(5):442-9.

44. Australian Institute of Health and Welfare. Indigenous Identification in hospital Separations Data-Quality Report. Catalogue No.: IHW 90. Canberra (AUST): AlHW; 2013.

45. Australian Institute of Health and Welfare. Regional and Remote Health:Indicators of Health System Performance. Canberra (AUST): AlHW; 2008.

46. Waddell C, Dibley M. The medicalization of aboriginal children: A comparison of the lengths of hospital-stay of aboriginal and non-aboriginal children in Western Australia and the Northern Territory. Aust Paediatr J. 1986;22(1):27-30.

47. Biddle N, Markham F. CAEPR Indigenous Population Project 2011 Census Papers. Paper 9 Mobility. Canberra (AUST): Australian National University Centre for Aboriginal Economic Policy Research; 2013.

48. Rothman KJ. No adjustments are needed for multiple comparisons. Epidemiology. 1990;1(1):43-6.

49. DiGuiseppi C, Goss C, Higgins JPT. Interventions for promoting smoke alarm ownership and function. Cochrane Database of Syst Rev. 2001;(2):CD002246.

50. Ehiri E, Ejere HOD, Magnussen L, Emus D, King W, Osberg JS. Interventions for promoting booster seat use in four to eight year olds travelling in motor vehicles. Cochrane Database Syst Rev. 2006;(1):CD004334. 
51. Martin J,CooperCD. Playground safety in SouthWestern Sydney. J Paediatr Child Health. 2005;41(11):587-91.

52. Sherker S, Ritchie J, Eager D, Dennis R. Soft landings: encouraging compliance with safety standards in Local Government Authority playgrounds. Health Promot $J$ Austr. 2009;20(1):31-6.

53. Vial D. Parks Base - State of the Sector Report on Playgrounds. Exploring Park Playground Planning and Management. Kenmore(AUST):Integrated Open Space Services; 2014.

54. Kidsafe NSW. Home and Community Safety Information Sheets. Westmead (AUST): Children's Hospital Westmead Kidsafe NSW; 2012 [cited 2016 Jun 22]. Available from: http://www.kidsafensw.org/ information-sheets/home-and-community-safety/

55 Kendrick D, Marsh P. Inequalities in receipt of injury prevention in primary care. Health Educ J. 2000;59: 150-6.

46. Kendrick D, Mulvaney C, Watson M. Does targeting injury prevention towards families in disadvantaged areas reduce inequalities in safety practices? Health Educ Res. 2009;24(1):32-41.

57. Australian Institute of Health and Welfare The Health and Welfare of Australia's Aboriginal and Torres Strait Islander People, An Overview. Canberra (AUST): AlHW; 2011.

58. Ingram JC, Deave T, Towner E, Errington G, Kay B, KendrickD. Identifying facilitators and barriers for home injury prevention interventions for pre-school children: A systematic review of the quantitative literature. Health Educ Res. 2012;27(2):258-68.

59. Smithson J, Garside R, Pearson M. Barriers to, and facilitators of, the prevention of unintentional injury in children in the home: A systematic review and synthesis of qualitative research. Inj Prev. 2011;17(2):119-26.

60 Keall MD, Pierse N, Howden-Chapman P, et al. Home modifications to reduce injuries from falls in the Home Injury Prevention Intervention (HIPI) study: A cluster-randomised controlled trial. Lancet. 2014;385(9964):231-8.

61. Hunter K, Keay L, Clapham K, et al. Buckle Up Safely (Shoalhaven): A process and impact evaluation of a pragmatic, multifaceted preschool-based pilot program to increase correct use of age-appropriate child restraints, traffic. Inj Prev. 2014;15(5):483-90.
62. Senserrick $T$, Hinchcliff $R$, Ivers $R$, Boufous $S$, Martiniuk A, Clapham K. Aboriginal Injury Prevention Projects: A Rapid Review. Sydney (AUST): The Sax Institute; 2010.

63. Clapham K, Khavarpour F, Bolt R, Stevenson M, Su S. Researching the safety of Indigenous children and youth: An urban perspective. In: McCoy BF, Stewart $\mathrm{P}$, Poroch N, ed. Urban Health: Strengthening Our Voice, Culture and Partnership. Canberra (AUST): Australian Institute of Aboriginal and Torres Strait Islanders; 2012. p. 47-57.

64. Clapham K, Bennett-Brook K, Callister C, Fildes D. Evaluation of the Illawarra Aboriginal Medical Service 'Safe Homes, Safe Kids' Program. Wollongong (AUST): University of Wollongong Australian Health Services Research Institute Centre for Health Services Development; 2015.

65. Ishikawa T, Oudie E, Desapriya E, Turcotte K, Pike I. A systematic review of community interventions to improve aboriginal child passenger safety. Am J Public Health. 2014;104 Suppl 3:e1-e8.

66. Giles AR, Hognestad S, Brooks LA. The need for cultural safety in injury prevention. Public Health Nurs. 2015;32(5):543-9.

67. Richardson F. Cultural safety in nursing education and practice in Aotearoa New Zealand. Whitireia Nurs J. 2011;18:44-7.

68. Department of Health. The Australian National Aboriginal and Torres Strait Islander Health Plan 20132023. Canberra (AUST): Government of Australia; 2013.

69. Pearson M, Hewson P, Moxham T, Taylor R. Review 2: A Systematic Review of Risk Factors for Unintentional Injuries Among Children and Young People Aged Under 15 Years. Quantitative Correlates Review of Unintentional Injury in Children. Exeter (UK): Peninsula Medical School Peninsula Technology Assessment Group; 2009.

70. Laflamme L, Hasselberg M, Reimers AM, Cavalini LT, Ponce de Leon A. Social determinants of child and adolescent traffic-related and intentional injuries: A multilevel study in Stockholm County. Soc Sci Med. 2009;68:1826-34.

\section{Supporting Information}

Additional supporting information may be found in the online version of this article:

Supplementary Table 1: ICD-10-AM external cause codes for grouping of injury mechanisms.

Supplementary Table 2: Rates of first unintentional injury hospitalisation for external cause groups and all unintentional injuries, in a cohort of children of Aboriginal and non-Aboriginal children in NSW, Australia, 2000-2014.

Supplementary Figure S2a: Rates of first unintentional injury hospitalisation for external cause groups in a cohort of Aboriginal and non-Aboriginal children in NSW, Australia, 2000-2014.

Supplementary Figure $\mathbf{S} \mathbf{2 b}$ : Rate ratios and $95 \%$ confidence intervals of injury hospitalisation by external cause groups in Aboriginal boys and girls compared with non-Aboriginal boys and girls in a cohort of children in NSW, Australia, 2000-2014.

Supplementary Table 3: Rates of first unintentional injury hospitalisation for injury mechanisms with $>5$ cases in any group of children, in a cohort of children of Aboriginal and non-Aboriginal children in NSW, Australia, 2000-2014.

Supplementary Figure S3: 20 leading injury mechanism in terms of absolute difference in hospitalisation rates (absolute inequality) between Aboriginal and non Aboriginal children. 